\title{
Labyrinthe
}

9| 2001

Numéro 9

\section{Les enjeux de l'analyse économique du droit}

Colloque L'Économie du droit dans les pays de droit civil : quelle place pour l'économie dans la construction des règles juridiques? organisé par le CREDES, Université de Nancy II, 28-29 juin 2000.

\section{Emmanuel Susset}

\section{OpenEdition}

\section{Journals}

Édition électronique

URL : http://journals.openedition.org/labyrinthe/1126

DOI : $10.4000 /$ labyrinthe. 1126

ISSN : 1950-6031

Éditeur

Hermann

Édition imprimée

Date de publication : 30 juin 2001

Pagination : 111-114

Référence électronique

Emmanuel Susset, «Les enjeux de l'analyse économique du droit », Labyrinthe [En ligne], 9 | 2001, mis en ligne le 11 février 2006, consulté le 19 avril 2019. URL : http://journals.openedition.org/ labyrinthe/1126; DOI : 10.4000/labyrinthe.1126

Ce document a été généré automatiquement le 19 avril 2019

Propriété intellectuelle 


\section{Les enjeux de l'analyse économique du droit}

Colloque L'Économie du droit dans les pays de droit civil : quelle place pour l'économie dans la construction des règles juridiques? organisé par le CREDES, Université de Nancy II, 28-29 juin 2000.

\section{Emmanuel Susset}

1 La science juridique est souvent critiquée pour son manque d'ouverture sur les autres disciplines. Conservateur par essence, selon l'expression de Georges Ripert ${ }^{1}$, le juriste serait rétif à toute tentative de pluridisciplinarité. En consacrant la domination du positivisme juridique, il aurait ainsi résolu le problème du fondement de la règle de droit, de ses rapports à loi naturelle et à la morale, et supprimé l'utilité de tout recours aux enseignements des autres disciplines. L'idée renvoie indirectement à la notion de droit formel développée par Max Weber pour désigner les règles obéissant uniquement à la logique juridique.

2 Cette analyse, si elle présente une part de vérité, ne décrit qu'imparfaitement l'état actuel de la doctrine française ainsi qu'en atteste le colloque international qui s'est tenu à Nancy en juin 2000. Organisé par le CREDES de l'Université de Nancy II, il avait pour thème d'étude l'analyse économique du droit ${ }^{2}$.

Cette notion est utilisée pour désigner un courant doctrinal, apparu aux États-Unis sous l'influence d'auteurs tels Richard Posner (Economic Analysis of Law, 1972) et Ronald Coase, dont l'ambition est d'appliquer au droit les outils et la méthode de la science économique. Il prétend apprécier les règles de droit en termes d'efficacité pour répondre à une triple finalité : critique (déterminer les effets non attendus d'une loi), normative (indiquer la législation qui devrait être adoptée) et prédictive (annoncer la législation qui sera retenue) ${ }^{3}$. Subversive à certains égards, la Law and Economics représente un défi pour le juriste français en ce qu'elle semble pouvoir remettre en cause les fondements de son système juridique écrit et codifié. En ce sens, cette école est perçue comme une manière détournée de légitimer la suprématie des droits anglo-américains. Elle peut également se heurter à la séparation stricte des enseignements universitaires en France. À cette 
dimension institutionnelle s'ajoute une certaine méfiance des juristes à l'égard des sciences économiques en raison de leur formalisation mathématique ${ }^{4}$.

L'un des mérites des organisateurs du colloque est d'avoir réuni des juristes et des économistes de nationalités différentes avec l'ambition de couvrir la quasi-totalité des branches du droit privé. L'analyse économique du droit ne se limite pas en effet à la seule réglementation de la concurrence, comme on pourrait le croire. Car si celle-ci constitue l'un des domaines dans lesquels elle est particulièrement adaptée, l'analyse économique du droit a vocation à embrasser aussi le droit des contrats, de la procédure civile ou de la responsabilité civile et pénale.

5 Pourtant, si elle suscite un intérêt certain dans la doctrine juridique française, l'analyse économique du droit demeure controversée. Madame Horatia Muir-Watt, professeur à l'Université de Paris I, analysa les forces de résistance présentes dans le droit civil français. Plus que de la discipline juridique elle-même, l'opposition provient d'une partie de la doctrine française. L'influence des spécificités culturelles ne doit pas être négligée, en particulier l'attachement à un certain idéal de justice poursuivi par le droit. En dehors de cette critique «finaliste», c'est l'un des fondements du paradigme de l'analyse néoclassique qui est remis en cause. Le rejet de la conception de l'individu véhiculée par la science économique (l'homo economicus, c'est-à-dire l'agent rationnel et maximisateur) conduisait ainsi Bruno Oppetit à considérer que « l'homme n'est pas réductible à la seule efficacité $»^{5}$. Les concepts de sujet de droit et d'agent économique ne seraient donc pas deux «représentations » équivalentes de l'être humain. Deux logiques difficiles à concilier s'affronteraient : celle du calcul économique et celle de la règle juridique.

6 Une certaine influence de l'analyse économique transparait néanmoins dans l'évolution de certaines règles du droit positif. Monsieur Jacques Ghestin, professeur émérite à l'Université de Paris I, démontra ainsi le lien qu'il est possible d'établir avec certaines règles de droit des contrats, telles celles applicables à leur cause et aux modalités de leur renégociation ${ }^{6}$. Ainsi, à propos de la notion de cause, la jurisprudence a-t-elle pris en compte l'objectif économique pour apprécier la validité du contrat ${ }^{7}$.

7 Il serait donc faux de penser que les juristes ont travaillé jusqu'ici sans se soucier de la dimension économique de la règle de droit ou sans tenter d'appréhender l'intérêt pour leur réflexion de l'analyse écnomique. Ils ont depuis longtemps pris conscience que le droit et l'économie ont en définitive un objet commun bien qu'elles l'envisagent sous un angle différent. C'est ainsi qu'en 1959 René Savatier s'interrogeait déjà sur les interactions existant entre les deux disciplines ${ }^{8}$.

$8 \quad$ Les enseignements que le droit peut tirer de la science économique peuvent donc être réels et intervenir à différents niveaux. Le colloque de Nancy a démontré la richesse de cet apport, qui renvoie d'ailleurs à la question de la scientificité de la discipline juridique. Espérons que la «science juridique » saura en profiter... pour mieux affirmer son identité. Tout l'enjeu serait alors de ne pas réduire le droit à une simple technique au service des conceptions économiques. Les lois juridiques ne s'identifient pas aux lois économiques !

9 Sur le thème de l'analyse économique du droit, on pourra se référer également à l'ouvrage récent Le Droit dans l'action économique, recueil d'articles publiés sous la direction de Thierry Kirat et d'Évelyne Serverin (C.N.R.S. Éditions, Paris, 2000). 


\section{NOTES}

1. Georges Ripert (1880-1958) fut doyen de la Faculté de droit de Paris et secrétaire d'État à l'Éducation de septembre à décembre 1940. Outre sa collaboration aux éditions successives du Traité élémentaire de droit civil de Marcel Planiol, il rédigea plusieurs ouvrages sur l'évolution du droit contemporain parmi lesquels Le Régime démocratique et le droit civil (1936) et La Règle morale dans les obligations civiles (1925).

2. Le colloque, qui s'étendait sur deux journées, était divisé en huit « ateliers »:1) Droits codifiés, mutations économiques et comparaisons internationales ; 2) Droit et réglementation de la concurrence ; 3) Théorie des obligations et coordination économique ; 4) Évolution des régimes de responsabilité et enjeux économiques ; 5) Procédure civile et justice ; 6) Décision judiciaire et jurisprudence ; 7) Droits de l'entreprise et réglementation économique ; 8) Sanctions pénales et infractions économiques. Un compte rendu des interventions peut être consulté sur le site Internet $\mathrm{du}$ CREDES.

3. Bruno Oppetit, Philosophie du droit, Dalloz, 1999, nº 52.

4. Sur cette question : Thierry Kirat, Économie du droit, Repères, La Découverte, 1999, p. 50 sqq.

5. Bruno Oppetit, « Droit et économie », Archives de philosophie du droit, Sirey, 1992, p. 19-28.

6. En vertu du principe de la force obligatoire du contrat (posé à l'article 1134 du Code civil : «Les conventions légalement formées tiennent lieu de loi à ceux qui les ont faites »), le contrat ne peut être modifié sans un commun accord des parties. La règle vaut même en cas d'imprévision c'est-à-dire de changement important de la situation économique et sociale par rapport à celle qui existait au moment de la conclusion du contrat. La partie qui pourrait en subir un préjudice ne peut imposer à l'autre une renégociation du contrat. La jurisprudence a paru infléchir le principe dans une décision de 1992. Dans cet arrêt du 3 novembre 1992, la Chambre Commerciale de la Cour de cassation a en effet affirmé l'obligation à la charge d'un fournisseur d'assurer à son distributeur (en l'espèce une station-service) des prix concurrentiels et donc de renégocier le contrat si cela était nécessaire en modifiant le prix des biens vendus.

7. Dans un arrêt célèbre, dit CHRONOPOST (du nom de l'entreprise de livraison rapide qui avait été assignée par son client), la Cour de cassation a refusé d'appliquer une clause exonératoire de responsabilité en reliant la notion de cause à celle d'obligation essentielle du contrat.

8. René Savatier, Les Métamorphoses économiques et sociales du droit privé d'aujourd'hui, seconde série, Paris, 1959, nº 61. D'autres juristes, à la même époque, ont eu une démarche similaire, tels Paul Durand (« La connaissance des phénomènes juridiques et les tâches de la doctrine moderne du droit privé », Recueil Dalloz 1956, Chronique 73), Jean Carbonnier (Théorie sociologique des sources du droit, Cours 1960-1961, p. 133) ou Jean Brethe de La Gressaye (« De la connaissance pratique du droit et de ses difficultés », Recueil Dalloz 1952, Chronique 89). 


\section{AUTEUR}

\section{EMMANUEL SUSSET}

Emmanuel Susset est allocataire moniteur normalien en droit privé à l'Université de Paris I. 